\title{
Mundos sociales y espacios festivos en el Yawar fiesta de José María Arguedas
}

\author{
Social Worlds and Festive Spaces in the Yawar fiesta of \\ José María Arguedas \\ Gerardo Castillo Guzmán \\ Pontificia Universidad Católica del Perú, Lima, Perú \\ Contacto: castillo.gm@pucp.edu.pe \\ https://orcid.org/0000-0002-2854-5585
}

\begin{abstract}
Resumen
El presente artículo $^{1}$ explora el mundo social que presenta José María Arguedas en su novela Yawar fiesta. Este es un mundo fragmentado en el cual interactúan diferentes arquetipos sociales en un universo fuertemente jerarquizado en el que, sin embargo, se comparten códigos culturales comunes que oponen al mundo andino de Puquio con elementos modernizantes de la costa. Finalmente, se concluye que la resolución de esta oposición cultural es lograda a través de la inversión carnavalesca del orden establecido.
\end{abstract}

Palabras claves: José María Arguedas; Yawar fiesta; Literatura peruana; Universos sociales; Carnaval.

\begin{abstract}
The following paper explores the social world that José María Arguedas constructs in his novel Yawar Fiesta. The depicted social world is a fragmented one where diverse social archetypes interact each other in a highly hierarchical universe where they share common cultural codes that oppose the Andean world of Puquio against modernizing elements of the coast. The paper concludes that the resolution of that cultural opposition is reached through the carnival reversal of the established social order.
\end{abstract}

Keywords: José María Arguedas; Yawar fiesta; Peruvian literatura; Social universes; Carnival.

Recibido: $13.11 .17 \quad$ Aceptado: 23.08.18 
Los temas del mestizaje, el dualismo entre lo occidental y lo indígena, junto con la modernización de la sociedad, han sido centrales en América Latina en general y en los países andinos en específico (Rowe, 1976). En el Perú existe una rica tradición de debate sobre el llamado problema indígena manifestada tanto en ensayos políticos (José de la Riva-Agüero, Manuel Gonzáles Prada, Víctor Andrés Belaunde o José Carlos Mariátegui, por ejemplo) como en obras literarias (Clorinda Matto de Turner, Luis Valcárcel, Enrique López Albújar o Ciro Alegría, solo para mencionar algunos autores centrales). Sin embargo, es José María Arguedas (1911-1969) quien ha logrado, de lejos, mayor notoriedad en el movimiento indigenista. Y ello no solo por su calidad literaria, sino también por representar un indigenismo más maduro y validado por la autoridad de un profundo conocimiento de las realidades andinas. La obra y vida misma de Arguedas están llenas de las contradicciones y las ambivalencias de un ser mestizo en tensión constante entre dos culturas (González Vigil, 1995).

Lecturas recientes han observado y criticado (Vargas Llosa, 1996), en la obra de Arguedas, la creación de un mundo dual entre indios y blancos en el cual es difícil plantear la figura intermedia del mestizo. El mundo arguediano se movería a través de una serie de encuentros violentos y de relaciones sociales excluyentes. Dada la posición personal del autor, que aboga abiertamente a favor de poblaciones indígenas andinas, entenderíamos sus intentos por incorporar el quechua en la narración en español (Bendezú, 1974) o por asociar a estos grupos con valores positivos en oposición a los sectores blancos. A partir de una lectura de Yawar fiesta, y sin pretender negar la pertinencia de interpretaciones previas, argumento que: a) el mundo social que presenta Arguedas es más fragmentado de lo que comúnmente se estima; b) diferentes arquetipos sociales interactúan en un universo fuertemente jerarquizado según opresivas relaciones de poder; c) sin embargo, se comparten códigos culturales comunes que oponen al mundo andino de Puquio con los elementos modernizantes de la costa, y; d) finalmente, la resolución de esta oposición cultural es lograda a través de la inversión carnavalesca del orden establecido. 


\section{Relaciones fragmentadas y universos culturales}

Tras un conjunto de cuentos (Agua, 1935), Yawar fiesta es la primera novela del autor. Si bien es cierto que lingüísticamente aún no logra la maestría en la construcción de un lenguaje literario que a través del castellano capture la expresividad quechua (Rodríguez Garrido, 1984) como lo alcanza en Los ríos profundos (1961) (Gonzáles Vigil, 1995), también es cierto que ella es una novela cuidadosamente pensada. Efectivamente, Arguedas escribe, modifica y madura la novela a lo largo de un período que va desde 1937 hasta la última revisión en 1958, aunque ya para 1941 tiene una versión más o menos definitiva (Muñoz, 1979).

Yawar fiesta posee una trama episódica y relativamente simple. Después de una presentación de la geografía, historia y sociedad del pueblo de Puquio, capital de la provincia de Lucanas en los Andes sur medio del Perú, el autor desarrolla el tema central. De entre los cuatro ayllus que integran Puquio -K'ollana, Chaupi, K'ayau y Pichk'achuri — destaca la rivalidad entre los dos últimos, la cual se evidencia en las corridas de toros que tienen lugar en las celebraciones de Fiestas Patrias o el día de la Independencia, los 28 de julio. Dispuestos a romper la ya tradicional racha de triunfos de los Pichk'achuris, los comuneros de K'ayau deciden capturar y torear al Misitu, un legendario toro bravío que reina en las punas de los K'oñanis. El anuncio causa revuelo en el pueblo e inmediatamente se establece una apuesta entre don Julián Arangüena — dueño del toro y el más temido gamonal— y don Pancho Jiménez —el comerciante mestizo - sobre si los de K'ayau serán o no capaces de capturar al animal. El subprefecto, sin embargo, apoyado en una directiva gubernamental, ordena la suspensión de la corrida por ser signo de barbarie y provocar matanzas entre los indios. El cuerpo mayor de la novela describe las veladas negociaciones y acomodos frente a la autoridad para llevar a cabo o impedir la corrida tradicional y cambiarla por una a "la española". El punto culminante ocurre cuando, ante el fracaso del torero traído desde Lima, los indios se apoderan de la situación y realizan finalmente la corrida. 
Esta simpleza narrativa es, no obstante, engañosa y ya desde las primeras páginas el lector es guiado por una voz que posee un simpatético y agudo conocimiento del paisaje:

Entre alfalfares, chacras de trigo, de habas y cebada, sobre una lomada desigual, está el pueblo.

Desde el abra de Sillanayok' se ven tres riachuelos que corren, acercándose poco a poco, a medida que van llegando a la quebrada del río grande. Los riachuelos bajan de las punas corriendo por un cauce brusco, pero se tienden después en una pampa desigual donde hasta una lagunita; termina la pampa y el cauce de los ríos se quiebra otra vez y el agua va saltando de catarata en catarata hasta llegar al fondo de la quebrada. (Arguedas, 1983, p. 71)

Sin embargo, el relato no se queda en la descripción paisajista y costumbrista que caracteriza a las literaturas indianista e indigenista. Discutiendo las referencias intertextuales en Los ríos profundos, Ricardo González Vigil (1995) ha señalado que Arguedas encuentra coincidencias al mismo tiempo que rechaza el purismo estético de José de la Riva-Agüero en su Paisajes peruanos (1955). Como acertadamente ha notado Peter Elmore (1993), desde el primer capítulo de Yawar fiesta se percibe un mundo social bastante más estratificado que la simple oposición entre indio explotado y blanco explotador, con la que buena parte de la literatura indigenista se valió para retratar su denuncia social. Por un lado, el narrador comprometido (Lewis, 1985) nos muestra una primera oposición geográfica y de incomprensión cultural entre el mundo costeño y el serrano:

Desde el abra de Sillanayok' se ven tres ayllus: Pichk'achuri, K'ayau, Chaupi.

- iPueblo indio! — dicen los viajeros cuando llegan e esta cumbre y divisan Puquio. Unos hablan con desprecio; tiritan de frío en la cumbre los costeños, y hablan:

— ¡Pueblo indio!

Pero en la costa no hay abras, ellos no conocen sus pueblos desde lejos. Apenas si en las carreteras los presienten, porque los caminos se hacen más anchos cuando la ciudad está cerca, o por la fachada de una hacienda próxima, por la alegría del corazón que conoce las 
distancias. ¡Ver nuestro pueblo desde un abra, desde una cumbre donde hay saywas de piedra, y tocar en quena o charango, o en rondín, un huayno de llegada! Ver a nuestro pueblo desde arriba, mirar su torre blanca de cal y canto, mirar el techo rojo de las casas, sobre la ladera, en la loma o en la quebrada, los techos donde brillan anchas rayas de cal; mirar en el cielo del pueblo, volando, a los killinchos y a los gavilanes negros, a veces al cóndor que tiende sus alas grandes en el viento; oír el canto de los gallos y el ladrido de los perros que cuidan los corrales. Y sentarse un rato en la cumbre para cantar de alegría. Eso no pueden hacer los que viven en los pueblos de la costa. (Arguedas, 1983, pp. 71-73)

El cuadro se complica aún más cuando a la oposición costa-sierra, el autor añade consideraciones de clase y posición social:

Desde las cumbres bajan cuatro ríos y pasan cerca del pueblo; en las cascadas, el agua blanca grita, pero los mistis no oyen. En las lomadas, en las pampas, en las cumbres, con el viento bajito, flores amarillas bailan, pero los mistis casi no ven. En el amanecer, sobre el cielo frío, tras del filo de las montañas, aparece el sol; entonces las tuyas y las torcazas cantan, sacudiendo sus alitas; las ovejas y los potros corretean en el pasto, mientras los mistis duermen, o miran, calculando la carne de los novillos. Al atardecer, el taita Inti dora el cielo, dora la tierra, pero ellos estornudan, espuelean a los caballos en los caminos, o toman café, toman pisco caliente. (Arguedas, 1983, p. 77)

A riesgo de ser esquemático en extremo es posible sostener que los personajes prototipo que Arguedas crea juegan sobre un doble eje racial y geográfico, como se resume en el cuadro 1.

\section{Cuadro 1. Arquetipos sociales en Yawar fiesta}

\begin{tabular}{l|l|l} 
& \multicolumn{1}{|c|}{ Sierra } & \multicolumn{1}{c}{ Costa } \\
\hline Indígena & $\begin{array}{l}\text { Pongos } \\
\text { Comuneros }\end{array}$ & $\begin{array}{l}\text { Migrantes pasivos } \\
\text { Migrantes revolucionarios }\end{array}$ \\
\hline Mestizo / Blanco & Mestizos & Juez, policía \\
& Gamonal tradicional & $\begin{array}{l}\text { Gamonal modernizante } \\
\text { Limeños }\end{array}$
\end{tabular}

Fuente: Elaboración propia. 
En un extremo tenemos a los pongos y los k'oñanis, pastores de puna que han perdido toda dignidad y sirven sumisamente a los gamonales. Los k'oñanis viven en permanente terror, tanto mítico hacia el toro, como terrenal frente el terrateniente. En ellos, el llorar es de mujerao, señal de debilidad, algo muy diferente a la viril sensibilidad de los indios comuneros. En estos últimos, Arguedas coloca los valores de resistencia, fuerza y acción colectiva que les permitieron, por ejemplo, construir la carretera a la costa en tan solo veintiocho días. Pero aún estos ayllus se encuentran diferenciados:

Tres ayllus se ven desde Sillanayok': Pichk'achuri, K'ayau, Chaupi. Tres torres, tres plazas, tres barrios indios. Los chaupis, de pretenciosos, techaron la capilla de su ayllu con calamina [...]

— itatao! — dicen los comuneros en los otros barrios-. Parece iglesia de misti.

Pero los chaupis están orgullosos de su capilla.

—Mejor que de misti —dicen ellos. (Arguedas, 1983, p. 72)

Además, los indios que migran a la ciudad también están representados. Efectivamente, la voz etnológica nos dice que dos mil lucainos vivían en Lima y más de quinientos eran de Puquio. Muchos de ellos sufren pasivos el ataque de la ciudad, no en vano el capítulo que Arguedas les dedica se titula "Los 'serranos"” con el comillado que habla del profundo desprecio que implica el término en la costa. Pero hay los otros que se organizan bajo una ideología revolucionaria marxista, aunque también enajenante.

Por otro lado, el mundo de los blancos y las autoridades es uno igualmente fragmentado. El capítulo sobre el despojo de tierras no deja dudas acerca de la condición opresora de los terratenientes, sin embargo, los procesos de modernización iniciados en la década de 1930 los afectan diferenciadamente. Con fuertes intereses económicos en la capital, muchos de ellos desarrollan hábitos culturales limeños y extranjerizantes, mientras que otros se aferran a un poder tradicional ejercido a través del ejercicio cotidiano de dominación en el pueblo 
y en las haciendas antes que a través de la adulación política. Las autoridades costeñas se encuentran ilustradas por el policía arequipeño con sentido del honor y el subprefecto iqueño obsesionado con su plan civilizador. La incomprensión del subprefecto no se limita a la corrida de toros, sino que abarca la totalidad de los pueblos andinos:

Mire que cielo para feo, qué pueblo más triste. A veces se me pone negro el humor entre estos cerros. Y pura aulladera de perros; $y$ cuando no los perros, esos cuernos que los indios tocan como para día de difuntos; o si no el viento que grita en la calamina. ¡Es una gran vaina! (Arguedas, 1983, p. 112)

Finalmente, el espacio intermedio de los mestizos es profundamente ambiguo y acomodaticio. De un lado:

Los chalos, según su interés, unas veces se juntan con los vecinos, otras veces con los ayllus...

Por las noches, los mestizos se reúnen a la puerta del billar y de las cantinas, para ver lo que juegan y lo que toman los mistis. A veces entran a las tiendas, se paran apoyándose en la pared, para no estorbar, y miran.

Cada vecino tiene tres o cuatro chalos de su confianza, y los mandan a cualquier parte, a veces de puro favor. En los días que llueve, los vecinos llaman en la calle a cualquier mestizo amigo de su casa y lo mandan por su abrigo, por su paraguas, cualquier mandato les ordenan. Entre ellos escogen los principales a sus mayordomos. A estos mestizos, que siguen como perros a los principales, los comuneros les llaman "k'anras", y quizá no hay en el hablar indio palabra más sucia. (Arguedas, 1983, pp. 76-77)

Así encontramos la figura del párroco, quien a pesar de ser de origen indio sirve de enlace e instrumento de dominación. Pero al mismo tiempo encontramos la figura del mestizo identificado con la cultura indígena:

[...] algunos mestizos son trabajadores; hacen negocio con los pueblos de la costa, llevando quesos, carneros, trigo, y trayendo cañazo de contrabando, velas, jabones.

Muchos de estos mestizos hacen amistad con los ayllus y hablan a favor de los comuneros. En los ayllus les llaman don Norberto, don Leandro, don Aniceto... 
Les hablan con respeto. Pero en las fiestas bailan con ellos, de igual a igual; y cuando hay apuro, el mestizo amigo aconseja bien, defiende a los ayllus. (Arguedas, 1983, p. 77)

En una sociedad rural como Puquio, fragmentada por relaciones de dominación y explotación, es un universo cultural compartido (el de la sierra peruana) el que le da unidad. En este sentido, la principal fuente de conflicto no es una oposición entre explotados (indios) y explotadores (la tríada indigenista del gamonal, la autoridad civil y el párroco), sino entre códigos culturales aparentemente irreconciliables: el mundo costeño y el mundo andino. De esta manera, el Yawar fiesta de Arguedas no equipara mundo andino con indio, sino que presenta un mundo más rico y jerarquizado, cohesionado por elementos culturales comunes. En voz del propio Arguedas: “[...] lo indígena está en lo más íntimo de toda la gente de la sierra del Perú" (citado por Rowe, 1976, p. 261).

Aunque la novela sigue explorando el viejo tema de civilizar a los indígenas de acuerdo con criterios occidentales —el conflicto entre civilización y barbarie (Arenas y Arenas, 1994, p. 520) - ella supera el arquetipo indigenista de la denuncia social a través de la oposición binaria entre el gamonal y el indio, entre el poder absoluto y la sumisión total sin vasos comunicantes. Arguedas crea una serie de modelos para cada mundo, les otorga lenguajes específicos que sirven como marcadores socioculturales y les concede diferentes valoraciones.

\section{Comunicación y violencia}

La dicotomía que presenta José María Arguedas no es entre dos tipos sociológicos, el indio explotado versus el blanco explotador, sino entre una cultura regional andina y una cultura regional costeña. Clave en este argumento es la escena final cuando don Antenor, el alcalde de Puquio, susurra al oído del subprefecto: “¿Ve usted, señor Subprefecto? Estas son nuestras corridas. ¡El yawar punchay verdadero!” (Arguedas, 1983, p. 192, énfasis nuestro). Existe pues un sentimiento, aunque teñido de paternalismo, de orgullo y pertenencia a una cultura andina compartida.

Por otro lado, encontramos la imposibilidad del subprefecto costeño de entender como algo más que una costumbre bárbara la corrida de toros indígena. 
No es de sorprender, entonces, que los gamonales alimeñados y los mestizos e hijos de comuneros que han migrado a Lima vean con idéntico valor negativo el turupukllay.

Lo que retrata Arguedas es un complejo sistema cultural al interior del cual existen relaciones jerarquizadas y abusivas de poder, pero en el cual es posible la comunicación gracias a códigos que comparten tanto los indios, como los hacendados y los mestizos, de ahí que uno de los mistis llegue a afirmar: "Pero la corrida es lo fuerte. Lo demás es ñagasa, ripio no más. Sin turupukllay, el 28 sería como cualquier día" (Arguedas, 1983, pp. 97-98).

Existiría, de esta manera, una degradación en la comunicación que va desde plena y fluida - en armonía con la naturaleza y lo cósmico, lograda por la sensibilidad de los comuneros - , hasta la trunca y fallida — representada por la imposibilidad del subprefecto por entender la cultura andina-.

Una de las tensiones más interesantes y reveladoras de las complejas relaciones de poder y unidad cultural en la novela la proporciona el diálogo que sostienen don Julián Arangüena (el gamonal por excelencia) y don Pancho Jiménez (el comerciante mestizo y ambiguo) cuando se encuentran encarcelados. Aquel detentaría el poder - aunque siempre precario y amenazado-, gracias al uso de la violencia, como el mismo don Julián lo reconoce:

[A los indios] los he acogotado feo. En su adentro, seguro, me maldicen. Es, pues, de razón. Yo, como a los perros no más los arreo. Ya usted sabe don Pancho, mucho hey fregado. Así es, pues. Dios me ha puesto en Puquio para que los aguantes. ¡Caray! Y en la puna, los hey hecho gritar bien, desde las alturas de Coracora hasta Chalhuanca, de Pampariche a Chipao. Como a potro mañoso los he amansado, así, a puro golpe, hasta que han arrodillado en el suelo. Usted es, pues, de otra manera, otro corazón tiene usted. Y es de razón. Usted ha hecho plata vendiendo trago y abarrotes no más; calladitos, y de buena voluntad, le han traído la ganancia a su misma casa. ¡Así cualquiera! Por eso, usted para de parte de los ayllus, es usted amiguero de K'ayau, de Pichk'achuri, y como a

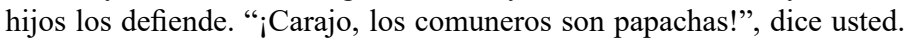
Y si hay ocasión usted pelea por la indiada. ¡Claro, pues! Así tiene que ser. Pero yo tengo correr la puna bien armao y tengo que meterles fuerte la espuela. (Arguedas, 1983, p. 182) 
En cambio, el comerciante basaría su ascendencia entre los comuneros no tanto por su diferente posición social y económica ya que, como lo evidencia el texto, no sería otra cosa que una más sutil forma de explotación, sino por su empatía y cariño con el indio. Con él comparte las mismas costumbres y sufre al no poder ser parte de ellas:

—iDon Julián! ¡Qué perra es mi suerte! ¡Quisiera estar allá, junto al coso! Regaría con aguardiente los pies de los k'ayaus; tocaría wakawak'ra con el Raura, con el Tobías.

[...] Por eso, cuando oyó el dinamitazo de media misa, se persignó de todo corazón. Quería ir a la corrida, no se sentía seguro de estar tranquilo en la cárcel, mientras el Misitu jugaba en el Pichk'achuri. (Arguedas, 1983, p. 184)

Aunque opuestos, entre ellos existe respeto mutuo. Lo sorprendente es que estos dos personajes centrales de la estructura social de Puquio y los pueblos andinos en general en la década de 1930 —el gamonal tradicional y el comerciante - son los que se oponen más fuertemente al subprefecto, la autoridad foránea e incapaz de entender la cultura local. Encarcelados por este, no asisten a la corrida de toros y escena final.

Haciendo eco a la esclarecedora apreciación de Antonio Cornejo Polar (1973) sobre la existencia de un ciclo de "ampliaciones sucesivas" en el trabajo de José María Arguedas, varios autores han notado un paralelismo entre la obra de Arguedas, su experiencia personal y los cambios socioeconómicos del Perú (Escajadillo, 1976; Flores Galindo, 1987; González Vigil, 1995). Si el Perú rural radicalmente se transforma en un efervescente mundo urbano fruto de masivas migraciones y la biografía de José María Arguedas va desde sus tiempos en Viseca y Puquio a los de Chimbote y Lima, su obra recorrería esta evolución: la vida comunal en Agua, los pueblos grandes del Yawar fiesta, la ciudad andina de Los rios profundos, hasta las ciudades de mestizos y migrantes de Lima y Chimbote en Todas las sangres (1964) y El zorro de arriba y el zorro de abajo (1971).

Estirando algo la idea de esta suerte de evolución o ampliación, es posible considerar Yawar fiesta como una transición en otros dos sentidos. Primero, la 
tensión entre el terrateniente y el comerciante proindígena, iniciada con la apuesta entre don Julián y don Pancho, no se soluciona y el mestizo permanece en una posición ambigua. Segundo, como explicaré líneas abajo, la oposición entre cultura andina y cultura foránea simbolizada en la corrida de toros no se resuelve meramente en el plano mítico, sino que la novela invoca la intervención de los indios, aunque sin llegar a la acción colectiva y consciente de los colonos presente en Los ríos profundos.

El sostener que Yawar fiesta supera las propuestas indigenistas previas no equivale a decir que la novela niegue la violencia sobre la que están basadas las relaciones sociales en Puquio. En realidad, es todo lo contrario, muchos de los dispersos episodios están articulados a través del tema de la autoridad y la validez de su ejercicio (Bourricaud, 1976). Así, en el despojo de tierras y pastos por parte de los gamonales se apela a una autoridad formal y legalista apoyada en el uso de la fuerza, aunque los ayllus conserven el uso del agua por la autoridad de la tradición y la fuerza de su número y tenacidad. El pueblo de Puquio, y sus cuatro ayllus, tiene la autoridad para ordenar a las demás comunidades de Lucanas la realización de faenas generales para la construcción de la carretera Puquio-Nazca, carretera que - como el estudiante revolucionario lo reconoce - no solo sirvió para que los gamonales lleven sus productos a Lima sino, muy especialmente, para que migrantes como él lleguen a la capital. El K'arwarasu goza de mayor respeto entre todos los demás apus y aukis en un sistema sagrado jerarquizado. El subprefecto basa su autoridad en ser funcionario de un Estado lejano y extraño (simbolizado por el retrato del presidente de la república, el cual cuelga silencioso en la sala de reuniones de la subprefectura) mientras los principales en su riqueza y arbitrariedad.

Arguedas utiliza la violencia para establecer un doble quiebre — social y cultural - que introduce la imperfección y, por tanto, la posibilidad de novelar; en los dos primeros capítulos Arguedas describe un pasado indígena ideal y armónico quebrado por el gamonalismo. Y el eje de la novela es logrado cuando la interferencia de autoridades modernizantes procura impedir una costumbre de siglos, el turupukllay. 
Como acertadamente observa Antonio Cornejo Polar (1976), la novela impone como unidad la vida total de los Andes sin borrar sus contradicciones internas. Mas al componer esta unidad andina la enfrenta al mundo costeño y civilizado, con lo cual la representación novelesca gana en densidad y riqueza. El complejo y paradójico simbolismo de la corrida de toros, entonces, manifiesta la oposición entre la cultura andina (asociada con lo indígena, local y duradero) y la cultura costeña (vinculada con lo occidental, foráneo y efímero), pero sin eliminar el conflicto latente entre indios y mistis. La imagen festiva del turupukllay no debe ser entendida como la eliminación de jerarquías sociales y creación de una hermandad indiferenciada, como lo propone Bajtin (1990) para el caso del carnaval europeo medieval. La distribución de los asientos en las graderías indica claramente el estatus de las personas y, aún más, muchos indios venidos de otras comarcas son simplemente excluidos del espectáculo de la corrida.

En Yawar fiesta las tensiones son puestas en relieve y la corrida da la oportunidad a los indios de expresar su rebeldía. Siguiendo la lectura del mismo Cornejo Polar (1976), los indios van a demostrar su coraje extremo, incluso a costa de su propia sangre, al matar con cargas de dinamita al toro que representa

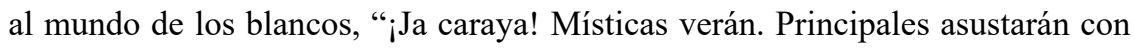
Misitu" (Arguedas, 1983, p. 94).

\section{Espacios festivos y subversión cultural}

La tradición indigenista ha echado mano de diversos recursos en su afán de resolver los conflictos presentados. Una de las formas más comunes ha sido el estallido de una rebelión generalizada o una gran matanza como final, lo que no hace sino presagiar mayor violencia; ello como muestra de la irreconciliable oposición entre lo indígena y lo blanco y la irreparable desaparición del elemento primero. Ejemplos de ello lo encontramos en El mundo es ancho y ajeno (1941) de Ciro Alegría, Huasipungo (1934) de Jorge Icaza, Raza de bronce (1919) de Alcides Arguedas o Redoble por Rancas (1970) de Manuel Scorza. En el Yawar fiesta, sin embargo, José María Arguedas utiliza lo festivo como posibilidad de resolución para las tensiones y el drama generados. Con ello no solo introduce 
en la literatura un elemento importantísimo de la cultura andina, sino que logra mayor profundidad y riqueza en el relato al proponer un final no cerrado, lleno de ambigüedades, donde lo extracotidiano y asombroso ingresa en la rutina de relaciones sociales y deja un espacio abierto para la incorporación de un diálogo con lo mítico, como posteriormente lo hará el propio Arguedas en El zorro de arriba y el zorro de abajo. No en vano James Higgins (1997) señala que el tema de la fiesta será retomado por autores posteriores, tal es el caso de La batalla (1954) de Carlos Eduardo Zavaleta o Taita Cristo (1960) de Eleodoro Vargas Vicuña. El mismo Arguedas, en Los ríos profundos, considera las chicherías (ubicadas en el barrio de Huanupata, un espacio liminal que no está ni en la ciudad, ni en la comunidad campesina, ni en la hacienda) fundamentalmente como un punto festivo y carnavalesco donde es posible el encuentro interétnico entre indios, cholos y mestizos gracias al alcohol, la música, el baile y una abierta sensualidad.

El que finalmente se realice la corrida de toros al modo indígena habla de la resistencia de su cultura. Ante el fracaso de Ibarito, el torero español, la corrida abandona el carácter de espectáculo para recuperar su condición de juego colectivo (Montoya, 1980, p. 58). Hasta los propios mistis gritan entusiasmados:

— iQue entre el "Honrao", carajo!

— iQue entre el Tobias! — gritó don Félix de la Torre.

—iQue entre el Wallpa!

—El K'encho! (Arguedas, 1983, p. 191)

No obstante, la corrida final ya no es la misma corrida indígena practicada en años anteriores, sino el producto mestizo de la negociación. Si bien conserva el espíritu original, ella se termina realizando en el coso pequeño y, más importante, es corrida solo por los toreros indios especialistas, con lo cual se elimina buena parte de la violencia y muerte implícitas. Por un lado, estos cambios simbolizan la capacidad de adaptación de la cultura andina y la posibilidad de concebir un sincretismo feliz que tome elementos occidentales dentro de la lógica estructurante indígena. Por otra parte, a un nivel más profundo, es el triunfo sobre lo salvaje y mítico que simboliza el Misitu. 
Efectivamente, el Misitu representa al Amaru, antiguo dios que tenía forma de serpiente y vivía en el fondo de los lagos, el cual fue transformado en toro según las creencias indígenas y habita en la sallk’a o puna salvaje:

Los k'oñanis decían que había salido de [la laguna] Torkok'ocha, que no tenía padre ni madre. Que una noche, cuando todos los ancianos de la puna eran aún huahuas, había caído tormenta sobre la laguna; que todos los rayos habían golpeado el agua, que desde lejos todavía corrían, alumbrando el aire, y se clavaban sobre las islas de Torkok'ocha; que el agua de la laguna había hervido alto, hasta hacer desaparecer las islas chicas; y que el sonido de la lluvia había llegado a todas las estancias de K'oñani. Y que, al amanecer, con la luz de la aurora, cuando estaba calmando la tormenta, cuando las nubes se estaban yendo del cielo de Torkok'ocha e iban poniéndose blancas con la luz del amanecer, ese rato, dicen, se hizo remolino en el centro del lago junto a la isla grande, y que de en medio del remolino apareció el Misitu, bramando y sacudiendo su cabeza. (Arguedas, 1983, p. 132)

Este ser asocial — sin padre ni madre-, de origen fabuloso, ha sido fecundado en la laguna por el rayo. En la mitología andina, el rayo o Illapa, por su forma zigzagueante y por caer del cielo hacia la tierra, es el opuesto de la serpiente o Amaru, quien sale del subsuelo. Posteriormente se ha asociado al rayo con Santiago, santo español usado en la saga de la conquista y rebautizado como Santiago Mataindios. Santiago también representa la introducción española del ganado vacuno y santiagos son los cantos de la época de herranza en la zona ayacuchana. No es sorprendente, entonces, el profundo miedo y reverencia que entre los pastores de la puna causa el Misitu. La muerte, primero del layk'a del K'arwarasu y luego la del propio Misitu, quiebra con el terror mítico que inspiran.

Los elementos carnavalescos de la escena final no se encontrarían tanto en la inclusión de elementos festivos y coloridos como en una estructura más sutil que subvierte el orden hegemónico. El toro simboliza en las sociedades andinas el poder de los españoles y, por extensión, de los gamonales. No es extraño que el Misitu, el toro más temido, sea propiedad de don Julián Arangüena, el temible gamonal y que sean sus pongos de puna los encargados de su cuidado. Es clara la 
asociación entre el terror y profundo respeto que sienten por el toro y la opresión, paternalismo y dependencia que sufren bajo el gamonal. No es casualidad entonces que don Pancho Jiménez llegue a decir: “-Usted, don Julián, es como un toro padre en Lucanas; se anda usted, de canto a canto, empujando a los otros, y abusando" (Arguedas, 1983, p. 182) ni que don Julián se emborrache lleno de orgullo: “- ¡Misitu! ¡No hay hombre para el Misitu! ¡Hasta las piedras le tiemblan, carajo! ¡Es de mí! ¡Es mi toro!” (Arguedas, 1983, p. 136).

Los indios comuneros libres son quienes romperán con esta opresión. Y lo hacen no en cualquier fecha, sino el 28 de julio, día de fiesta nacional en el que se celebra la independencia política de España. De tal manera, la novela conecta esta lucha local con una condición nacional de liberación. Comentando su propia obra, Arguedas señala que el verdadero personaje:

[...] es la masa indígena que destruye el mito que está representado por el toro, el Misitu. Cuando el pueblo indígena quiere mostrar su valor ante la gente que lo desprecia, que son los señores, incluso mata a un dios, que es el Misitu, e incluso está dispuesto a matar a sus dioses para demostrar que son gentes que tienen valor [...]. (Citado por Escajadillo, 1976, pp. 87-88)

No sería en vano que Arguedas no elija al danzaq o danzante de tijeras para representar la resistencia indígena, a pesar de ser personaje central de la cultura quechua de Lucanas, como bien lo ha notado Martin Lienhard (1983). Al igual que el turupukllay, el danzaq es una construcción sincrética que toma elementos de la vestimenta española dentro de una estructura ritual agraria andina. Pero a diferencia del mismo, la competencia entre danzaqs no opone al mundo andino con lo español, sino a sectores del universo indígena. Sin embargo, en el turupukllay narrado, Arguedas no utiliza al cóndor en la lucha contra el toro, como es característico de muchas corridas en los departamentos de Ayacucho y Apurímac y que él mismo incluyó en su cuento Yawar fiesta anterior. De esta manera, el antagonismo en la novela no se queda en el mero plano simbólico, sino que requiere de la acción colectiva de los indios comuneros, quienes vencerán al elemento opresor español en el día de la independencia nacional. 


\section{Conclusión}

Yawar fiesta de José María Arguedas no solo compone un complejo microcosmos de la sociedad andina, sino que delinea buena parte de los elementos centrales de su trabajo literario posterior. Estos son: los problemas de comunicación cultural en condiciones de violencia y opresión, la acción colectiva como fuerza liberadora, la resistencia y posibilidad de la cosmovisión andina y, en términos narrativos, la incorporación del quechua al castellano - tanto en el ámbito de contenido como de estructura - y la voz etnológica comprometida.

A diferencia de la tradición indigenista que compone tipos sociológicos opuestos, Arguedas construye universos culturales dentro de los cuales interactúan sus arquetipos sociales. Aunque escape por completo del objetivo de este artículo, podría sostenerse que el énfasis que el autor coloca en las caracterizaciones culturalistas no solo corresponde a sus preocupaciones como escritor y a su experiencia personal como mestizo viviendo entre dos culturas, sino que es también parte de un contexto mayor del canon antropológico de la época.

Yawar fiesta es una obra en transición - incluso por su extensión, que la convierte en una nouvelle - y buena parte de ello se debe a la estructura liminal de la corrida de toros. Gracias al recurso de lo carnavalesco, de la inversión de mundos, Arguedas logra trascender el plano puramente mítico para insertar la trama en la historia. El turupukllay se transforma en alegoría de la resistencia de lo indígena frente a lo occidental y de la capacidad de adaptación de la cultura andina. Al colocar la muerte del Misitu en manos de los carismáticos toreros indígenas, Arguedas abandona el mito y avanza hacia la rebelión consciente.

\section{Nota}

1 Este artículo se basa en el trabajo realizado en el curso Latin American Novel dirigido por Ismael Márquez en el primer semestre del año 2002 en The University of Oklahoma. Al profesor Márquez le agradezco sus oportunos comentarios y sugerencias. 


\section{Referencias bibliográficas}

Arenas, M. A., \& Arenas, M. I. (1994). Identidad y presencia social del indio en dos novelas de Arguedas: Yawar fiesta y Los ríos profundos. Thesaurus, 49 (3), 519-526.

Arguedas, J. M. (1983). Obras completas. Tomo II. Lima, Ed. Horizonte.

Bajtin, M. (1990). La cultura popular en la edad media y en el renacimiento: el contexto de Francois Rabelais. Trad. J. Forcat \& C. Conroy. Madrid: Alianza Editorial.

Bendezú Aibar, E. (1974). Yawar fiesta: espejo quechua de José María Arguedas. Ínsula, 29(332-333), 9 y 23.

Bourricaud, F. (1976). El tema de la violencia en Yawar fiesta. En J. Larco (comp. y pról.), Recopilación de textos sobre José María Arguedas (pp. 209222). La Habana: Centro de Investigaciones Literarias Casa de las Américas.

Cornejo Polar, A. (1973). Los universos narrativos de José María Arguedas. Buenos Aires: Losada.

Cornejo Polar, A. (1976). El sentido de la narrativa en Arguedas. En J. Larco (comp. y pról.), Recopilación de textos sobre José María Arguedas (pp. 45-72). La Habana: Centro de Investigaciones Literarias Casa de las Américas.

Elmore, P. (1993). Los muros invisibles: Lima y la modernidad en la novela del siglo XX. Lima: Mosca Azul y El Caballo Rojo.

Escajadillo, T. G. (1976). Las señales de un tránsito a la universalidad. En J. Larco (comp. y pról.), Recopilación de textos sobre José María Arguedas (pp. 73-110). La Habana: Centro de Investigaciones Literarias Casa de las Américas.

Flores Galindo, A. (1987). El Perú hirviente de estos días...: una reflexión sobre violencia política y cultura en el Perú contemporáneo. En J. Klaiber 
(coord.), Violencia y crisis de valores en el Perú (pp. 197-233). Lima: Pontificia Universidad Católica del Perú y Fundación Tinker.

González Vigil, R. (1995). Introducción. En J. M. Los ríos profundos (pp. 9-108). Madrid: Cátedra.

Higgins, J. (1997). El tema del yawar fiesta en la narrativa peruana del 50. En J. Aladro-Font. (ed. e int.), Homenaje a don Luis Monguió (pp. 233-246). Newark: Cuesta.

Lewis, T. K. (1985). Arguedas the Innovator: Yawar Fiesta and 'Tupac Amaru Kamaq Taytanchisman'. Discurso Literario, 3(1), 97-109.

Lienhard, M. (1983). La función del danzante de tijeras en tres textos de José María Arguedas. Revista Iberoamericana, 49(122), 149-157.

Montoya, R. (1980). Yawar fiesta: una lectura antropológica. Revista de Crítica Literaria Latinoamericana, 6(12), 55-68.

Muñoz, S. (1979). Yawar fiesta: el mito de la salvación por la cultura. Texto Crítico, 5(14), 71-103.

Riva-Agüero, José de la. (1955). Paisajes peruanos. Lima: Imprenta Santa María.

Rodríguez Garrido, J. A. (1984). Las variantes textuales de Yawar fiesta de José María Arguedas. Lexis, 8(1-2), 1-93 y 175-225.

Rowe, W. (1976). Mito, lenguaje e ideología como estructuras literarias. En J. Larco (comp. y pról.), Recopilación de textos sobre José María Arguedas (pp. 257-283). La Habana: Centro de Investigaciones Literarias Casa de las Américas.

Vargas Llosa, M. (1996). La utopía arcaica: José María Arguedas y las ficciones del indigenismo. Ciudad de México: Fondo de Cultura Económica. 